\title{
Relationship Between Glycosylation of Haemoglobin and the Duration of Diabetes: A Study During the Third Trimester of Pregnancy
}

\author{
H. Madsen ${ }^{1,2}$, J.-J.Kjærgaard ${ }^{1}$ and J. Ditzel ${ }^{1}$ \\ ${ }^{1}$ Department of Medicine, Section of Endocrinology and Metabolism \\ and ${ }^{2}$ Department of Obstetrics and Gynecology, Aalborg Regional Hospital, Aalborg, Denmark
}

\begin{abstract}
Summary. The relationship between blood glucose and glycosylated haemoglobin $\left(\mathrm{HbA}_{1 \mathrm{c}}\right)$ has been investigated during an 8 week period in 53 Type 1 (insulin-dependent) diabetic women studied during the third trimester of pregnancy. Blood glucose estimations (fasting and $2 \mathrm{~h}$ post-prandially) were made an average of 41 times in each patient during this period and $\mathrm{HbA}_{\mathrm{lc}}$ was determined once at the end of the study. There was a significant correlation between both the mean blood glucose over the preceding 8 weeks and the standard deviation of the fasting blood glucose with $\mathrm{HbA}_{\mathrm{Ic}}(r=0.69, p<0.001 ; r=$ $0.46, p<0.001$, respectively). A 'glycosylation index' was calculated for each patient $\left(\mathrm{HbA}_{\mathrm{lc}}\right.$ divided by the mean blood glucose value). There was a significant correlation between the 'glycosylation index' and duration of diabetes $(r=0.68, p<0.001)$. In contrast, there was no correlation between red cell 2,3-diphosphoglycerate and $\mathrm{HbA}_{\mathrm{lc}}$ or 'glycosylation index'. These findings suggest that increasing duration of diabetes influences the post-translational formation of $\mathrm{HbA}_{\mathrm{Ic}}$ and that isolated $\mathrm{HbA}_{\mathrm{lc}}$ values need to be interpreted with caution in the pregnant diabetic.
\end{abstract}

Key words: Haemoglobin $A_{1 c}$, duration of diabetes, diabetic pregnancy, glycosylation index, 2,3-diphosphoglycerate.

Glycosylation of haemoglobin, leading to the formation of haemoglobin $A_{1 c}\left(\mathrm{HbA}_{1 c}\right)$, is increased in diabetic patients [1]. It has been shown that $\mathrm{HbA}_{\mathrm{lc}}$ is formed by a non-enzymatic, post-translational reaction during the 120-day life span of the erythrocyte [2]. The mean blood glucose concentration of the preceding 1-2 months is the major known factor influencing the glycosylation of haemoglobin in vivo in both non- pregnant $[3,4]$ and pregnant diabetics [5]. Thus, glycosylated haemoglobin seems to be an indicator of blood glucose regulation of the preceding 1-2 months in diabetes. Studies in vitro have shown that the glycosylation of haemoglobin is impaired by carbon monoxide and 2,3-diphosphoglycerate (2,3-DPG) [6]. At present, no other factors are known to influence the glycosylation of haemoglobin. Recently, however, we found in a study of pregnant diabetics, that the same average blood glucose levels over the preceding 8 weeks could lead to quite variable levels of $\mathrm{HbA}_{\mathrm{Ic}}$ in different patients [7].

The purpose of the present study was to evaluate the possible effect of red cell 2,3-DPG and duration of diabetes on the glycosylation of haemoglobin.

\section{Subjects and Methods}

The subjects studied were 53 pregnant patients with well established Type 1 (insulin-dependent) diabetes before this pregnancy. The clinical features of the patients studied are shown in Table 1. The patients were classified according to White [8]. None of the patients had severe anaemia or suffered from renal insufficiency. In the third trimester venous blood samples for determinations of $\mathrm{HbA}_{\mathrm{lc}}$ and red cell 2,3-DPG were taken in the morning after the usual morning insulin dose and a light breakfast. These determinations were preceded by frequent capillary blood glucose determinations (mean 4l, range 21-60 mmol/1), taken fasting at $0700 \mathrm{~h}$ and $2 \mathrm{~h}$ postprandially at $1430 \mathrm{~h}$ for a period of 8 weeks. All blood samples were taken in hospital. The diabetes was treated according to Pedersen [9]. The patients were given five daily meals. Forty-seven received two insulin injections and six one injections per day, usually of a small amount of crystalline insulin mixed with NPH.

The levels of $\mathrm{HbA}_{\mathrm{Ic}}$ were determined by the macrocolumn chromatographic method of Trivelli et al. [10] as modified by Schwartz et al. [11]. The haemolysates were dialyzed for $18 \mathrm{~h}$ at $4{ }^{\circ} \mathrm{C}$ against 1000 volumes of glucose-free $42 \mathrm{mmol}$ phosphate buffer (pH6.70) which was also used to elute $\mathrm{HbA}_{\mathrm{lc}}$ during chromatography. Biorex-70 was used as the ion exchange resin. The coefficient of variation by this method in our laboratory is $2.5 \%$. Normal values for pregnant women are $4.0 \pm 0.7 \%$ (mean \pm SD). Capillary blood 
Table 1. Clinical features and results of the patients studied

\begin{tabular}{|c|c|c|c|c|c|c|c|c|c|}
\hline & \multirow{2}{*}{$\begin{array}{l}\text { Age } \\
\text { (years) }\end{array}$} & \multirow{2}{*}{$\begin{array}{l}\text { Duration of } \\
\text { diabetes } \\
\text { (years) }\end{array}$} & \multirow{2}{*}{$\begin{array}{l}\text { Insulin dose } \\
\text { (U) }\end{array}$} & \multirow{2}{*}{$\begin{array}{l}\mathrm{HbA}_{i \mathrm{c}} \\
(\%)\end{array}$} & \multicolumn{3}{|c|}{ Blood glucose $(\mathrm{mmol} / \mathrm{l})$} & \multirow{2}{*}{$\begin{array}{l}\text { Standard } \\
\text { deviation of } \\
\text { fasting blood } \\
\text { glucose } \\
(\mathrm{mmol} / \mathrm{l})\end{array}$} & \multirow{2}{*}{$\begin{array}{l}2,3-\mathrm{DPG} \\
(\mu \mathrm{mol} / \mathrm{g} \\
\mathrm{Hb})\end{array}$} \\
\hline & & & & & Fasting (f) & $\begin{array}{l}\text { Post-prandial } \\
\text { (p) }\end{array}$ & $\begin{array}{l}\text { Average } \\
(f+p)\end{array}$ & & \\
\hline Mean & 25.5 & 9.6 & 54.6 & 7.1 & 6.2 & 7.4 & 6.8 & 1.9 & 17.1 \\
\hline$\pm \mathrm{SD}$ & 4.6 & 5.6 & 22.4 & 1.2 & 1.7 & 2.0 & 1.3 & 1.0 & 1.3 \\
\hline \multirow[t]{3}{*}{ Range } & $18-42$ & $1-23$ & $8-112$ & $4.9-11.0$ & $3.1-11.0$ & $2.9-12.4$ & $4.3-10.5$ & $0.3-5.4$ & $14.7-20.4$ \\
\hline & \multicolumn{4}{|c|}{ White classification } & & \multicolumn{3}{|l|}{ Retinopathy } & \\
\hline & $\begin{array}{l}\text { White B } \\
14\end{array}$ & $\begin{array}{l}\text { White C } \\
12\end{array}$ & $\begin{array}{l}\text { White D } \\
22\end{array}$ & $\begin{array}{l}\text { White F } \\
5\end{array}$ & & $\begin{array}{l}\text { Absent } \\
26\end{array}$ & $\begin{array}{l}\text { Background } \\
22\end{array}$ & $\begin{array}{l}\text { Proliferative } \\
5\end{array}$ & \\
\hline
\end{tabular}

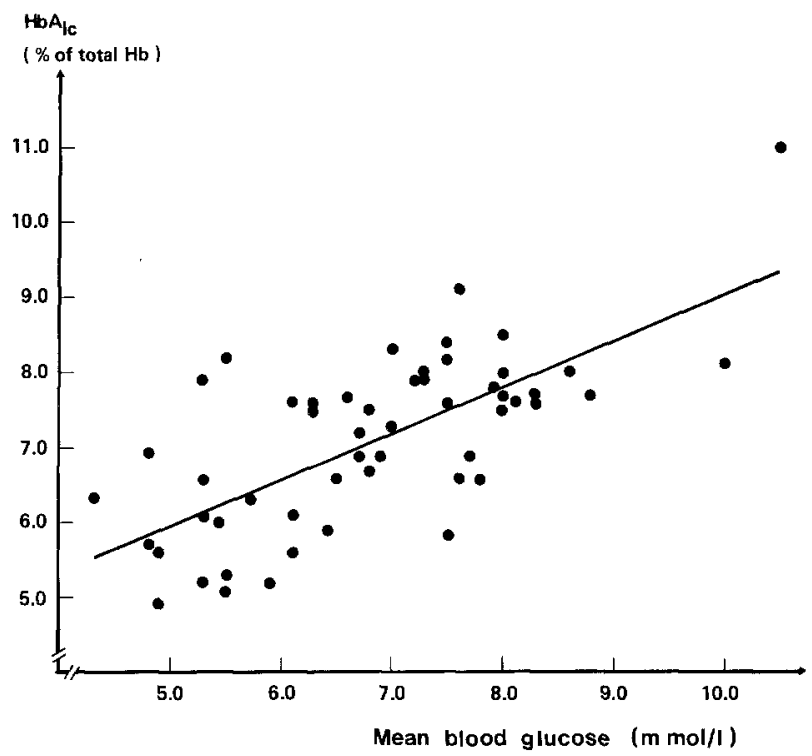

Fig. 1. Relationship of $\mathrm{HbA}_{\mathrm{lc}}$ to mean blood glucose levels in the preceding 8 weeks in 53 pregnant diabetic subjects $(y=0.61 x+$ $2.92, r=0.69, p<0.001$ )

glucose was measured with a glucose dehydrogenase procedure using Technicon autoanalyzer [12].

Red cell 2,3-DPG concentrations were determined by an enzymatic method according to Ericsson and deVerdier [13]. The coefficient of variation is $2.1 \%$ and normal values of pregnant women are $16.0 \pm 1.7 \mu \mathrm{mol} / \mathrm{g}$ haemoglobin.

One possible method for detecting other influences on the formation of $\mathrm{HbA}_{l \mathrm{c}}$ apart from blood glucose per se, is to calculate a 'glycosylation index' by dividing $\mathrm{HbA}_{\mathrm{lc}}$ by the mean blood glucose level of the preceding 8 weeks.

Statistical correlations were performed by linear regression analysis.

\section{Results}

Table 1 presents the mean $\pm \mathrm{SD}$ values for $\mathrm{HbA}_{1 \mathrm{c}}$, blood glucose (fasting and $2 \mathrm{~h}$ post-prandially), standard deviation of fasting blood glucose and 2,3-DPG.
There was a significant correlation between $\mathrm{HbA}_{\mathrm{lc}}$ and mean blood glucose of the preceding 8 weeks $(r=0.69, p<0.001 ;$ Fig. 1$)$. In addition, the standard deviation of fasting blood glucose (in absolute units) correlated significantly with $\mathrm{HbA}_{1 \mathrm{c}}(r=$ $0.46, p<0.001)$ and the mean blood glucose $(r=0.48$, $p<0.001)$. The correlation between standard deviation of fasting blood glucose and $\mathrm{HbA}_{1 \mathrm{c}}$ persisted when the standard deviation was expressed as a percentage of the mean fasting blood glucose (i.e. "correcting' for the level of glycaemia), although this correlation was weak $(r=0.35, p<0.01)$. From Figure 1 it can also be observed, that $\mathrm{HbA}_{\mathrm{lc}}$ values may vary by approximately $50 \%$ for the same mean blood glucose concentration in different patients.

Red cell 2,3-DPG was not correlated to $\mathrm{HbA}_{1 \mathrm{c}}$ $(r=0.07, \mathrm{NS})$ or to 'glycosylation index' $(r=0.04$, NS). No correlation was found between the duration of diabetes and the actual $\mathrm{HbA}_{\mathrm{lc}}$ level $(r=0.02$, NS). However, a significant correlation was present between the duration of diabetes and 'glycosylation in$\operatorname{dex}^{\prime}(r=0.68, p<0.001$; Fig. 2$)$.

The subjects were divided into two groups; group 1 consisting of 23 patients with duration of diabetes less than 10 years and group 2 of 30 patients with duration of diabetes of 10 years or more. The correlation between $\mathrm{HbA}_{\mathrm{ic}}$ and mean blood glucose for each group was higher than for the collective material (group 1: $r=0.80, p<0.001$; group 2: $r=0.79, p<$ 0.001 ; Fig. 3). The regression line for the group with longer duration of diabetes was placed significantly higher than that of the group with shorter duration of the disease $(p<0.001)$. There was no difference between the slopes of the regression lines.

The standard deviation of fasting blood glucose did not correlate with the duration of diabetes, neither when the standard deviation was expressed in absolute units $(r=0.06, \mathrm{NS})$. nor as a percentage of the mean fasting blood glucose $(r=0.22, \mathrm{NS})$. 


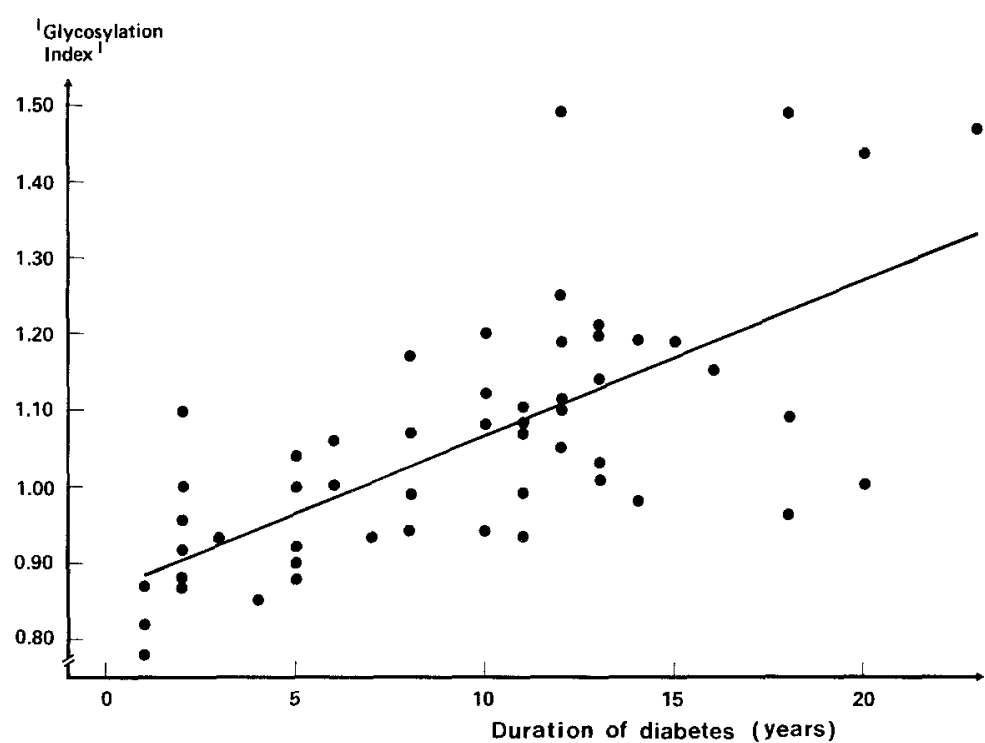

Fig. 2. Relationship of 'glycosylation index' to the duration of diabetes in 53 pregnant diabetic subjects $(y=0.02 x+0.87, r=0.68, p<0.001)$

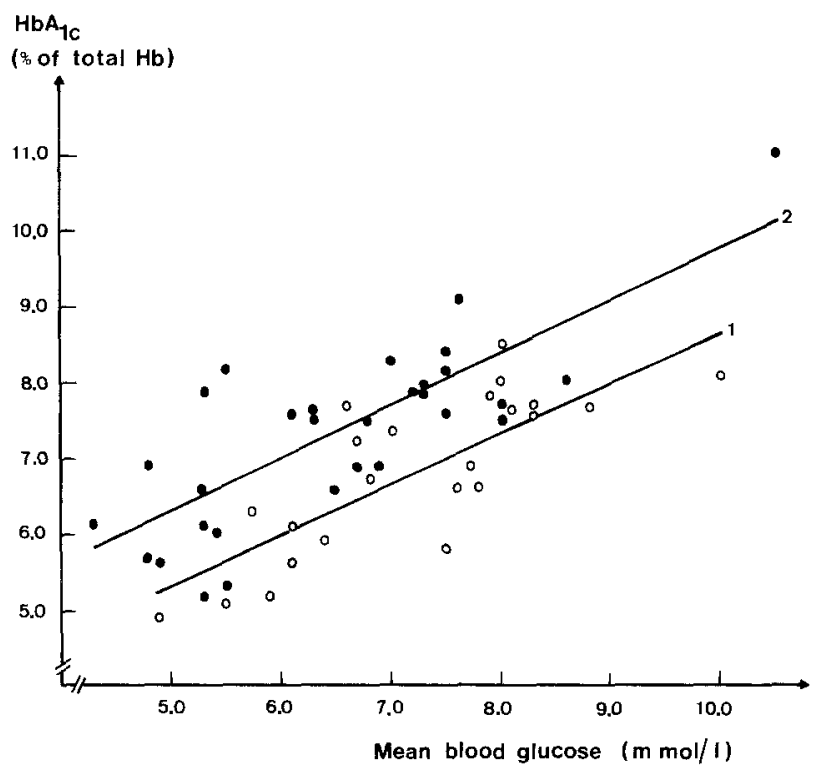

Fig. 3. Relationship of $\mathrm{HbA}_{1 \mathrm{c}}$ to mean blood glucose levels in the preceding 8 weeks for group $1(\mathrm{O})(y=0.69 x+1.84, r=0.80$, $p<0.001)$ and group $2(-)(y=0.71 x+2.70, r=0.79, p<0.001)$. (See text)

\section{Discussion}

This study confirms the results of others that $\mathrm{HbA}_{\mathrm{Ic}}$ is related to the mean blood glucose of the preceding 8 weeks [3-5]. However, as indicated in the present study and in those of others [3-5], $\mathrm{HbA}_{\mathrm{lc}}$ may vary markedly (by approximately $50 \%$ ) for similar mean blood glucose levels from one patient to another, suggesting that the glycosylation process of haemoglobin might also be influenced by factors other than preceding blood glucose level. These variations might be partly explained by the inherent inaccuracy of deter- mining the actual variation in blood glucose through the $24 \mathrm{~h}$ period on the basis of a few seperate measurements. The method for determining $\mathrm{HbA}_{\mathrm{lc}}$ used in this study included $18 \mathrm{~h}$ of dialysis of the haemolysate against a glucose-free medium. This procedure minimizes the effect of short term changes in blood glucose on the level of $\mathrm{HbA}_{1 \mathrm{c}}[14,15]$. In a study of nonpregnant diabetic patients, we recently found that $\mathrm{HbA}_{\text {Ic }}$ correlated significantly with the standard deviation of fasting blood glucose, suggesting that the more variable the blood glucose, the stronger its effect on the glycosylation of haemoglobin [16]. The same correlation between standard deviation of fasting blood glucose and $\mathrm{HbA}_{\mathrm{lc}}$ was found in the present study of pregnant diabetic patients. A correlation of similar magnitude was also present between the standard deviation and mean blood glucose levels. Thus, it cannot be decided whether variations per se influence the glycosylation of haemoglobin. However, the slight correlation between $\mathrm{HbA}_{\mathrm{lc}}$ and standard deviation of fasting blood glucose, expressed as a percentage of the mean fasting blood glucose, may indicate a weak influence of blood glucose variation on the glycosylation process.

From studies in vitro, it is known that 2,3-DPG impairs the glycosylation of haemoglobin [6]. In the present study such a negative relationship between red cell 2,3-DPG and the glycosylation process could not be demonstrated. However, as glycosylation occurs throughout the 120-day life span of the erythrocyte and 2,3-DPG was only determined once during this period, our study does not exclude an influence of 2,3-DPG on the formation of $\mathrm{HbA}_{1 \mathrm{c}}$.

In the study of Trivelli et al. [10] $\mathrm{HbA}_{\mathrm{lc}}$ was not found to be related to the duration of diabetes. In a recent study by Goldstein et al. [17] on 180 children and 
adolescents with diabetes mellitus, a slight but significant correlation $(r=0.34)$ between $\mathrm{HbA}_{1 \mathrm{c}}$ and the duration of diabetes was found. In this study we did not find any such correlation. However, we found that the 'glycosylation index' was strongly related to the duration of diabetes, which may indicate that the rate of glycosylation increases with duration of the disease. The underlying reason for this finding is not known. In our study we made no correction for haemoglobin $\mathrm{F}$, which co-elutes with $\mathrm{HbA}_{1 \mathrm{c}}$ on Biorex macrocolumns. However, haemoglobin $\mathrm{F}$ in normal pregnancy rarely exceeds $0.5 \%$ [18] and no evidence is available to indicate that haemoglobin F is increased in diabetic pregnancy [11]. Though haemoglobin F may theoretically increase with duration of diabetes, it is unlikely that this would explain the present finding. As we found no correlation between the variability of blood glucose and duration of diabetes, it is not likely either, that the duration effect can be explained by increasing variability of blood glucose with duration of diabetes. A possible biological explanation for our finding may be a decreasing ability of the individual to secrete insulin. To determine whether the duration effect on the glycosylation of haemoglobin in diabetes is an isolated phenomenon during pregnancy requires further investigation.

Pregnancy is a period in which blood glucose must be strictly regulated to obtain the best prognosis for the fetus and newborn infant $[8,9]$. As $\mathrm{HbA}_{1 c}$ is related to time-integrated blood glucose, $\mathrm{HbA}_{1 \mathrm{c}}$ has been suggested as a valuable tool in optimising blood glucose regulation. However, because the glycosylation of haemoglobin seems to vary from one patient to another, possibly due to the influence of the duration of the disease, a single $\mathrm{HbA}_{\mathrm{lc}}$ determination cannot satisfactorily predict the degree of regulation. Our experience suggests that, besides frequent blood glucose determinations, $\mathrm{HbA}_{1 \mathrm{c}}$ should be determined once or twice-weekly throughout the pregnancy.

Acknowledgements. This investigation was supported in part by the Northern Jutland Medical Research Fund and the Research Fund of Aalborg City Council. The expert technical assistance of Esther Ditzel, Gitte Dahl Hansen, Hanne Jensen and Anne Madsen is gratefully acknowledged.

\section{References}

1. Bunn HF, Gabbay KH, Gallop PM (1978) The glycosylation of hemoglobin: Relevance to diabetes mellitus. Science 200: $21-27$

2. Bunn HF, Haney DN, Kamin S, Gabbay KH, Gallop PM (1976) The biosynthesis of human hemoglobin $\mathrm{A}_{1 \mathrm{c}}$ : Slow glycosylation of hemoglobin in vivo. J Clin Invest 57:1652-1659
3. Koenig RJ, Peterson CM, Jones RL, SaudekC, Lehrmann M, Cerami A (1976) Correlation of blood glucose regulation and hemoglobin $A_{\mathrm{Ic}}$ in diabetes mellitus. $N$ Engl J Med 295: $417-420$

4. Gabbay KH, Hasty K, Breslow JL, Ellison RC, Bunn HF, Gallop PM (1977) Glycosylated hemoglobins and long-term blood glucose control in diabetes mellitus. J Clin Endocrinol 44: 859-864

5. Kjærgaard J-J, Ditzel J (1979) Hemoglobin $A_{1 c}$ as an index of long-term blood glucose regulation in diabetic pregnancy. Diabetes 28: 694-696

6. Haney DN, Bunn HF(1976) Affinity labeling of hemoglobin by glucose-6-phosphate. Proc Natl Acad Sci USA 73: 3534-3538

7. Madsen H, Ditzel J, Hansen P, Hahnemann N, Andersen OP, Kjærgaard J-J (1981) Hemoglobin $A_{1 c}$ determinations in diabetic pregnancy. Diabetes Care 4: 541-546

8. White P (1971) Pregnancy in diabetes. In: Marble A, White P, Bradley RF, Krall LP (eds) Joslin's Diabetes mellitus, 11th edit. Lea and Febiger, Philadelphia, pp 581-598

9. Pedersen J (1977) The pregnant diabetic and her newborn, 2nd edit. Munskgaard, Copenhagen

10. Trivelli LA, Ranney HM, Lai HJ (1971) Hemoglobin components in patients with diabetes mellitus. N Engl J Med 284: 353-357

11. Schwartz HC, King KC, Schwartz AL, Edmunds D, Schwartz R (1976) Effects of pregnancy on hemoglobin $A_{l c}$ in normal, gestational diabetic and diabetic women, Diabetes 25: 1118-1122

12. Banauch D, Brümmer W, Ebeling W, Metz H, Rindfrey H, Lang H, Leybold K, Rick W (1975) Eine Glucose-dehydrogenase für die Glucose-Bestimmung in Körperflüssigkeiten. Z Klin Chem Klin Biochem 13:101-107

13. Ericsson A, deVerdierCM (1972) A modified method for the determination of 2,3-diphosphoglycerate in erythrocytes. Scand J Clin Lab Invest 29:85-90

14. Widness JA, Royler-Brown TL, McGormick KL, Petzold KS, Susa JB, Schwartz HC, Schwartz R (1980) Rapid fluctuations in glycohemoglobin (hemoglobin $\mathrm{A}_{\mathrm{lc}}$ ) related to acute changes in glucose. J Lab Clin Med 95: 386-394

15. Ditzel J, Kjærgaard JJ, Reiko Kawahara, Østergaard GZ, Mourits-Andersen T (1981) Glycosylated hemoglobin in relation to rapid fluctuations in blood glucose in children with insulin-dependent diabetes. A comparison of methods with and without prior dialysis. Diabetes Care 4:551-555

16. Kjærgaard JJ, Hansen P, Madsen H, Ditzel J (1980) Hemoglobin $A_{l c}$ as an indicator of long term blood glucose levels in diabetics with special reference to diabetic pregnancy. Acta Endocrinologica 94 (Suppl 238): 25-29

17. Goldstein DE, Walker B, Rawlings SS, Hess RL, EnglandJD, Peth SB, Hewett JE (1980) Hemoglobin $A_{1 c}$ levels in children and adolescents with diabetes mellitus. Diabetes Care 3: 503-507

18. Ruchnagel DL, Chernoff AJ (1955) Immunologic studies of hemoglobin. III Fetal hemoglobin changes in the circulation of pregnant women. Blood 10:1092-1099

Received: 28 April 1981

and in revised form: 16 July 1981

Dr. J. Ditzel

Section of Endocrinology

Department of Medicine

Aalborg Regional Hospital

DK-9000 Aalborg, Denmark 